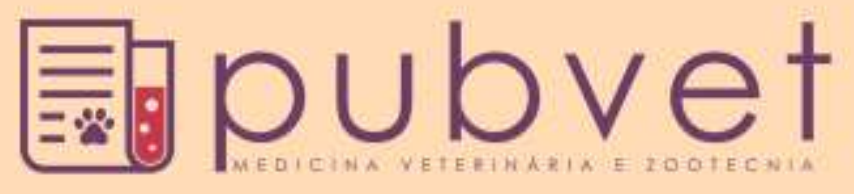

HTTP://DX.DOI.ORG/10.22256/PUBVET.V11N2.276-280

\title{
Cão portador de Linfossarcoma atendido no Hospital Veterinário da Anhanguera - SP: Relato de caso
}

\author{
Fernanda de $\operatorname{Mattos}^{1} \&$ Eduardo Reis ${ }^{2}$ \\ ${ }^{I}$ Aluna do curso de Medicina Veterinária, Universidade Anhanguera (UNIAN), São Bernardo do Campo, Brasil \\ ${ }^{2}$ Docente do curso de Medicina Veterinária, Universidade Anhanguera (UNIAN), São Bernardo do Campo, Brasil \\ Autor para correspondência:_efe_mattos@hotmail.com
}

\begin{abstract}
RESUMO. Os linfomas (linfomas ou linfossarcomas) são um grande grupo de neoplasias que têm em comum a sua origem, as células linforeticulares, e surgirem devido a uma proliferação clonal descontrolada deste tipo de células. Nos canídeos, o linfoma representa aproximadamente $18 \%$ de todas as neoplasias malignas e $80 \%$ dos tumores hematopoiéticos. O diagnóstico de linfoma é realizado através de punção aspirativa por agulha fina para avaliação citológica do respectivo linfonodo, massa ou órgão afetado e deve incluir exame físico completo, execução de um perfil hematológico e bioquímico, urianálise, radiografia abdominal e/ou ultrassonografia e radiografia torácica. Depois do diagnóstico estabelecido, deve ser determinado o estadiamento do linfoma. A quimioterapia sistêmica continua a ser o tratamento de eleição para o linfoma canino e a combinação de vários protocolos tem uma maior eficácia comparativamente ao uso de apenas um quimioterápico. O objetivo deste trabalho foi apresentar o relato de caso de um cão de quatro anos de idade com diagnóstico histológico de Linfossarcoma e o protocolo de quimioterápicos.
\end{abstract}

Palavras chave: Cão, eutanásia, linfoma

\section{Lymphosarcoma in dog attended at the Veterinary Hospital of Anhanguera-Brazil: Case report}

\begin{abstract}
Lymphomas (lymphomas or lymphosarcomas) are a large group of neoplasias that have their origin in common, lymphoreticular cells, and arise due to an uncontrolled clonal proliferation of this type of cells. In canids, lymphoma accounts for approximately $18 \%$ of all malignancies and $80 \%$ of hematopoietic tumors. The diagnosis of lymphoma is performed by fine needle aspiration for cytological evaluation of the respective lymph node, mass or organ affected and must include a complete physical examination, hematological and biochemical profile, urinalysis, abdominal radiography and/or ultrasonography and chest X-ray. After established diagnosis, staging of the lymphoma should be determined. Systemic chemotherapy continues to be the treatment of choice for canine lymphoma and the combination of several protocols has a greater efficacy compared to the use of only one chemotherapeutic. The aim of this work is a case report of a dog of four years of age with histological diagnosis of lymphosarcoma.
\end{abstract}

Keywords: Dog, necropsia, lymphomas

\section{Linfosarcoma en perro atendido en el Hospital Veterinario de Anhanguera - Brasil: Reporte de caso}


RESUMEN. Los linfomas (linfomas o linfosarcomas) son un gran grupo de neoplasias que tienen en común su origen, as células linforreticulares, y se desarrollan debido a una proliferación clónica descontrolada de este tipo de células. En los cánidos, el linfoma representa aproximadamente $18 \%$ de todas las neoplasias malignas y $80 \%$ de los tumores hematopoyéticos. El diagnóstico de linfoma es realizado a través de punción e aspiración con aguja fina para evaluación citológica del respectivo ganglio linfático, masa u órgano afectado y debe incluir examen físico completo, ejecución de un perfil hematológico y bioquímico, análisis de orina, radiografía abdominal e/o ultrasonografía e radiografía torácica. Después del diagnóstico establecido, debe ser determinada el estado del linfoma. La quimioterapia sistémica continua a ser el tratamiento elegido para el linfoma canino y la mezcla de varios protocolos tiene una mayor eficacia comparativamente con el uso de apenas una terapia química. El objetivo de este trabajo fue presentar el reporte de caso de un perro de cuatro años de edad con diagnóstico histológico de Linfossarcoma y su respectivo protocolo de quimioterapia.

Palabras clave: Perro, necropsia, linfoma

\section{Introdução}

O linfoma maligno ou linfossarcoma constitui um grande grupo de neoplasias que partilham a mesma origem, as células linforeticulares (Ettinger and Feldman, 2004). Surgem devido a uma proliferação clonal descontrolada deste tipo de células, normalmente com início nos tecidos linfoides (linfonodos e baço) podendo, contudo surgir em qualquer tecido do organismo (Nelson and Couto, 2015).

As neoplasias hematopoiéticas são o terceiro tipo de neoplasias mais comuns diagnosticadas no cão. O linfoma é o tumor hematopoiético mais frequente em ambas as espécies, sendo que a leucemia, outras doenças mieloproliferativas e o mieloma múltiplo ocorrem mais raramente.

Este trabalho teve como objetivo avaliar o relato de caso envolvendo um paciente cão SRD macho de 4 anos, diagnosticado de Linfoma de grandes células, pela análise do histopatológico admitido no Hospital Veterinário da Anhanguera UNIAN - SP no período do $2^{\circ}$ semestre, bem como o protocolo de quimioterápicos.

\section{Relato de caso}

Um cão macho de quatro anos de idade, sem raça definida (SDR) foi admitido no Hospital Veterinário da Anhanguera UNIAN - SP no segundo semestre de 2016, Prontuário 19618. Ao exame clínico o animal apresentava desidratação leve, hiporexia, emese (só quando comia), fezes pastosas (coloração preta), polidpsia, taquipnéia, hipofonese dos sons cardíacos e respiratórios, estertores pulmonares, com a palpação foram notados linfonodos subescapulares aumentados e finalmente foi observado que o animal apresentava um tumor na região da traqueia com aumento de volume nos linfonodos.

Após o acompanhamento do caso clínico e discussão com os médicos veterinários no cumprimento do estágio obrigatório do Hospital Faculdade Anhanguera de São Paulo - UNIAN; no HOVET foram autorizadas as análises que incluíram exame físico completo, perfil hematológico (Tabela 1 e Tabela 2), análise de líquidos cavitarios (Tabela 3.), análise de citologia 1 nódulo, ultrassonografia (Tabela 4) e ecocardiograma.

Tabela 1. Eritograma de paciente canino sem raça definida

\begin{tabular}{lcc}
\hline Hemograma & Valores obtidos & $\begin{array}{c}\text { Valores } \\
\text { referencia }\end{array}$ \\
\hline Hemácias & 4,90 & $5,7-7,4$ milhões $/ \mathrm{mm}^{3}$ \\
Hemoglobina & 12,00 & $14-18 \mathrm{G} / \mathrm{dL}$ \\
Hematócrito & 35,00 & $38-47 \%$ \\
VCM & 71,43 & $63-77 \mathrm{fL}$ \\
HCM & 24,49 & $21-26 \mathrm{pgG}$ \\
CHCM & 34,29 & $31-35 \%$ \\
Proteinas totais & 6,20 & $6,0-8,0 \mathrm{mg} / \mathrm{dL}$ \\
Metarrubrícitos & \multicolumn{2}{c}{$0 \%$} \\
\hline Fonte: Universidade Anhanguera - São Paulo
\end{tabular}

Dos linfonodos pré-escapulares direito e esquerdo foi realizada uma citologia aspirativa com agulha fina de linfonodos (em média duas lâminas por linfonodo palpável) com fixação de Metanol e coloração de panótico para analise histopatológico. O tumor foi submetido a uma punção aspirativa a qual foi encaminhado ao laboratório de patologia Vet Dyagnostico para exame anátomo patológico. 
Tabela 2. Leucograma de Paciente canino sem raça definida

\begin{tabular}{lcccc}
\hline \multirow{2}{*}{ Leucograma } & \multicolumn{2}{c}{$\begin{array}{c}\text { Valores } \\
\text { obtidos }\end{array}$} & \multicolumn{2}{c}{$\begin{array}{c}\text { Valores de } \\
\text { referência }\end{array}$} \\
\cline { 2 - 5 }$\%$ & $\mathrm{~mm} 3$ & $\%$ & $\mathrm{~mm} 3$ \\
\hline Leucócitos & & $18-200$ & & $6000-16000$ \\
Mielócitos & & & & \\
Metamielócitos & & & & \\
Bastonetes & & & $0-1$ & $0-300$ \\
Segmentados & 72 & 13104 & $55-80$ & $3000-11400$ \\
Eosinófilos & 9 & 1638 & $1,0-9,0$ & $100-750$ \\
Basófilos & & 0 & $0-1$ & Raros \\
Linfócitos típicos & 8 & 1456 & $13-40$ & $1000-4800$ \\
Linfócitos atípicos & & 0 & & \\
Monócitos & 11 & 2002 & $1,0-6,0$ & $150-1350$ \\
\hline
\end{tabular}

Fonte: Universidade Anhanguera - São Paulo

Nos exames de amostras fibrina plaquetárias foi notado uma discreta Anisocitose e Policromasia. Ou seja; na Anisocitose uma anormalidade de tamanho das células vermelhas do sangue. Já na parte ultrassonográfica foi laudado um aumento homogênico de radiopacidade com campos pulmonares, em região cranial, mais evidentes em hemotórax esquerdo neoformação.
No exame macroscópico observou-se a presença de efusão neoplásica de células epitelioides, podendo favorecer origem neuroendrócrina analisada de acordo com os métodos convencionais.

Microscopicamente, tratava-se de pequenos agrupados de células epiteloides. Estas apresentavam discretas anisocitose e anisocariose, discretamente poligonais. Escasso citoplasma geralmente basofílico claro com bordos pouco definido e não vacuolizados. Núcleo arredondados a ovalados com cromatina pouco grosseira e nucléolos inconspícuos. Não foram observadas figuras de mitose. $\mathrm{O}$ exame revela linfoma de grandes células, com aspectos morfológicos compatíveis com tumor maligno que acometem os linfonodos e outros órgãos.

Inicialmente o paciente foi tratado com Aldactone $25 \mathrm{mg} / \mathrm{kg}$, e $1 \frac{1}{2}$ comprimido a cada 12 horas (BID), Furosemida 40/mg/kg 1 comprimido a cada 12 horas (BID) e RX de tórax - 3 projeções e drenagem do líquido do pescoço. Posteriormente o paciente foi submetido á vários procedimentos quimioterápicos no combate ao linfoma.

Tabela 3. Análise de líquidos cavitarios de paciente canino sem raça definida

\begin{tabular}{lccc}
\hline Parâmetro & Transudato & Transudato modificado & Êxsudato \\
\hline Proteina total & $<2,5$ & $2,5-7,5$ & $>3,0$ \\
Ctcn (cels totais) & $<1.500$ & $1.000-7.000$ & $>7.000$ \\
Densidade & $<1017$ & $1017-1025$ & $>1025$ \\
Bactérias & Ausentes & Ausentes & Variável \\
Células predominantes & Mononucleadas e mesoteliais & Monócitos, mesoteliais, & Neutrófilos, macrófragos \\
hemácias e linfócitos & e mesoteliais \\
\hline $\begin{array}{l}\text { OBS: Mesoteliais células com núcleos grandes e redondos encontrados em líquidos cavítarios Fonte: Universidade Anhanguera - São } \\
\text { Paulo }\end{array}$
\end{tabular}

Tabela 4. Laudos ultrassonográficos paciente canino sem raça definida

\begin{tabular}{ll}
\hline Órgão & \multicolumn{1}{c}{ Laudo } \\
\hline Bexiga & Presença de conteúdo anecogênico; moderadamente repleta; sem sedimentos de litíase vesical \\
Rim & Simétrico; Estrutura arredondada; Padrão vascular preservada \\
Baço & Contornos regulares; Dimensões aumentadas; vascular preservado \\
Estômago & Repleto de conteúdo gasoso; Estratificação mantida; Paredes normoespessa \\
Fígado & Repleto de conteúdo anecogêmico regulares; Dimensões mantidas; Paredes finas e regulares \\
Alças & Sem alteração topográfica; Estratificação mantida; Paredes normais normoespessa \\
Testículos & Orquectomizado (castrado); Ausência de bolsa escrotal \\
Próstata & Não caracterizada \\
Glândulas adrenais & Não visualizado \\
Pâncreas & Sem alterações topográficas \\
\hline
\end{tabular}

Fonte: Universidade Anhanguera - São Paulo

Para o procedimento Quimioterápico foi aplicado os seguintes fármacos: Vineristina 0,75 $\mathrm{mg} / \mathrm{kg}$ IV com associação Ondansetron $0,5 \mathrm{mg} / \mathrm{kg}$
10 minutos antes da aplicação de doxorrubicina $30 \mathrm{mg} / \mathrm{kg}$ IV e prometazina- $0,5 \mathrm{mg} / \mathrm{kg}$, que tem 
como finalidade o alivio da dispneia sofrido pelo animal.

Durante o acompanhamento do estado crítico do paciente foi observado de maneira delicada que o mesmo não apresentava uma melhora substancial no combate a doença, uma vez que o mesmo foi submetido às diversas drenagens na cavidade torácica devido ao acumulo de líquidos (Figura 1, Figura 2A 2B).

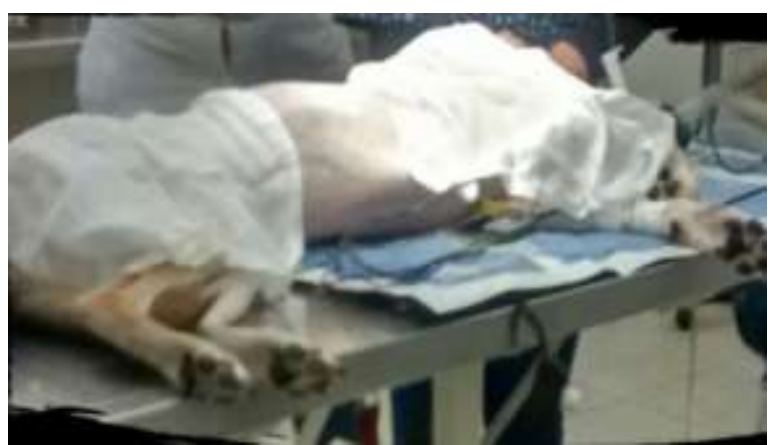

Figura 1. Paciente canino sem raça definida 4 anos de idade, na mesa cirúrgica para o procedimento de drenagem na cavidade torácica . Fonte: Universidade Anhanguera - São Paulo

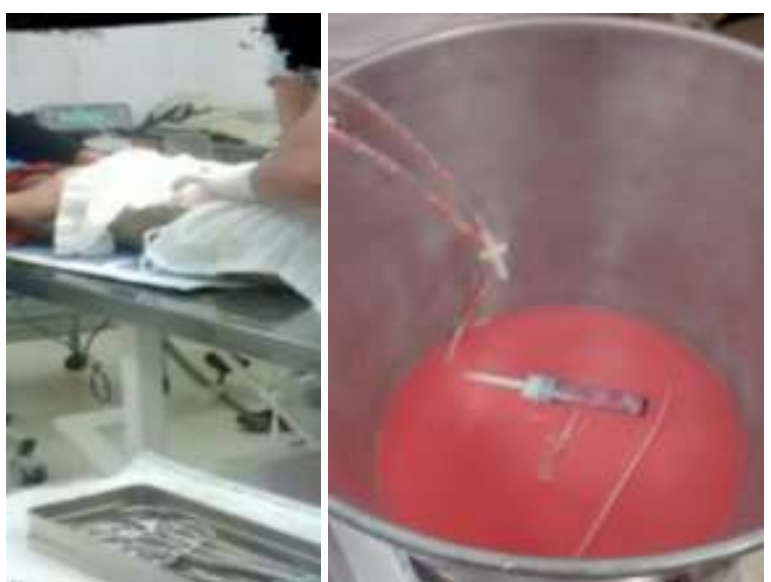

Figura 2. Toracocentese e aspecto de liquido toraxico de paciente canino sem raça definida 4 anos de idade. A. Drenagem na cavidade torácica na região lateral esquerda. B. Líquido drenado da cavidade torácica com aspecto rosada, 400 ML. Fonte: Universidade Anhanguera - São Paulo

Passados vários dias observou-se uma piora no quadro clínico evidenciando uma angustia respiratória e sofrimento constante do paciente e paralelamente a drenagem do liquido torácico foi sendo cada vez mais, se mostrando difícil, visto que se formou uma cadeia de fibrina

Desta forma, o proprietário em consonância com a equipe de médicos veterinários decidiu assinar o termo de consentimento do procedimento para realização da eutanásia do animal (Figura 3).

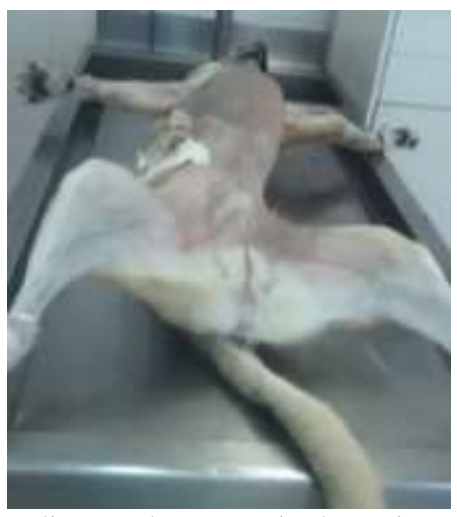

Figura. 3. Realização da necropsia de paciente canino sem raça definida de 4 anos de idade. Fonte: Estudo em aula no mês de setembro 2016 -Universidade Anhanguera - São Paulo

Na necropsia foi informado pelo patologista a síndrome da veia cava superior (Figuras 4), isso ocorre lentamente e incluem dificuldade para respirar ou falta de ar, tosse e inchaço da face. A veia cava superior, que drena para o átrio direito do coração, pode ser comprimida quando um tumor cresce dentro do tórax. Os tipos de câncer que podem causar a síndrome são o de pulmão e o linfoma não Hodgkin, além das metástases (Wurschmidt et al. 1995; Lazzarinni, et al. 1993; Urban, et al. 1993).

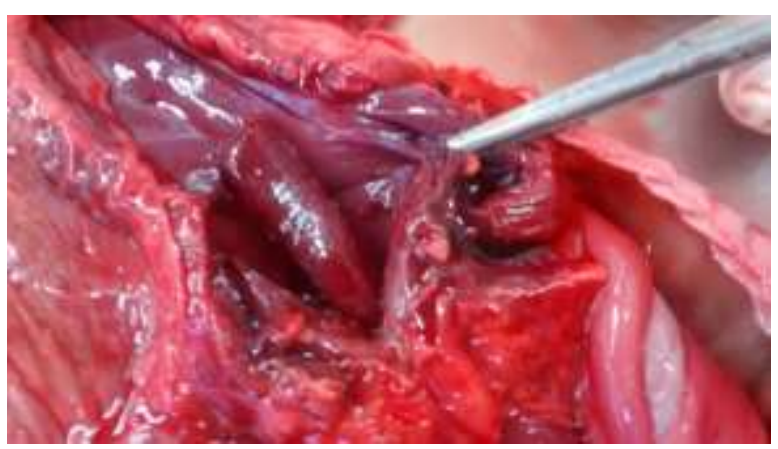

Figura 4. Achado no procedimento da necropsia da veia cava superior no paciente canino sem raça definida de 4 anos de idade. Fonte: Universidade Anhanguera - São Paulo.

Segundo Fighera et al. 2006 a presença de células macro e microscópicas são comuns em Neoplasias que afetam o sistema linfático em cães de meia idade e idosos, sendo na maioria dos casos de natureza idiopática.

As células neoplásicas têm, frequentemente, características morfológicas de um dos estádios de ativação ou transformação que a célula sofre após exposição ao antígeno, ou seja, são grandes linfócitos, alguns em mitose, com núcleos duplos e nucléolos evidentes (Rapaport, 1990) 


\section{Conclusão}

Podemos concluir que de fato embora tenha feito o tratamento quimioterápico, sua estimativa de vida varia de dois meses até dois anos. O animal deve ser tratado até o momento em que a doença ou o próprio tratamento cause danos ao organismo incompatíveis com a vida e que levem o cão ao sofrimento. Só nesse caso; a Eutanásia é indicada.

\section{Referências Bibliográficas}

Ettinger, S. \& Feldman, E. 2004. Tratado de medicina interna veterinária: doenças do cão e do gato. Guanabara Koogan, Rio de Janeiro.

Nelson, R. W. \& Couto, C. G. 2015. Medicina interna de pequenos animais. Elsivier Editora, Amsterdan.

Urban, T., Lebean B. \& Chastang C. 1993. Superior vena cava syndrome in small cell lung cancer. Archives of Internal Medicine, 153, 384.

Wurschmidt, F., Bunemann, H. \& Heilmann, H.P. 1995. Small cell lung cancer with and without superior vena cava syndrome: a multivariate analysis of prognostic factors in 408 cases. International Journal of Radiation Oncology Biology and Physics, 33, 77.
Lazzarinni, M., Orlandi, E. \& Paulli, M. 1993. Primary mediastinal B cell lymphoma with sclerosis: an aggressive tumor with distinctive clinical and pathologic features. Journal Clinical Oncology, 11,2306

Fighera RA, Souza TM, Rodrigues A \& Barros CSL. 2006. Aspectos clinicopatológicos de 43 casos de linfoma em cães. MEDVEP - Revista Cientifica de Medicina Veterinaria de Pequenos Animimaies de Estimação, 4, 139146

Rapaport, S. 1990. Hematologia Introdução $2^{a}$ ed., Roca, São Paulo, Brasil. 472p.

\section{Article History:}

Received 10 October 2016

Accepted 31 November 2016

Available on line 16 February 2017

License information: This is an open-access article distributed under the terms of the Creative Commons Attribution License 4.0, which permits unrestricted use, distribution, and reproduction in any medium, provided the original work is properly cited. 